\title{
Analysis of Interventions for Improving Cervical-Cancer Screening Uptake among Nigerian Women
}

\section{Nwobodo HA ${ }^{*}$ and Maryam Ba-Break ${ }^{2}$}

${ }^{1}$ Department of Medical Microbiology, College of Medicine, Enugu State University of Science and Technology, Enugu State, Nigeria

${ }^{2}$ Nuffield Centre for International Health and Development, Leeds Institute of Health Sciences, University of Leeds, United Kingdom

\section{Review Article}

Volume 1 Issue 2

Received Date: June 16, 2017

Published Date: July 15, 2017

DOI: $10.23880 /$ phoa-16000107

*Corresponding author: Nwobodo Humphrey Afam, Department of Medical Microbiology, College of Medicine, Enugu State University of Science and Technology, Enugu State, Nigeria, Tel: +234-8036688783, E-mail: humphreyafam@yahoo.com

\section{Abstract}

Cervical-cancer is preventable through early detection of cervical intraepithelial neoplasia that heralds the disease via cervical-cancer screening, yet its mortality is still high especially in developing countries. In Nigeria, researchers have attributed the high cervical-cancer mortality to low uptake of cervical-cancer screening predicated on wrong perception and low knowledge of cervical-cancer and cervical-cancer screening; lack of cervical-cancer screening programme; inadequate community support for cervical-cancer screening and gap in screening skills among health-workers where opportunistic cervical-cancer screening exists. This study aims to identify context-specific interventions for improving cervical-cancer screening uptake and reducing cervical-cancer burden in Nigeria. Secondary data was used for the study. Literature were obtained from Global Health, Popline and PubMed databases; WHO and other relevant websites using Eldis search engine; and from libraries in the University of Leeds and WHO in Geneva. Interventions for improving cervical-cancer screening uptake were analyzed using a set of appraisal criteria which include; technical and cost effectiveness, organizational, gender, cultural and political feasibility to determine their applicability and transferability in Nigeria. Broad interventions identified are; intervention aimed at correcting perception, improving knowledge and increasing access to cervical-cancer screening. Reducing the burden and impact of cervical-cancer in Nigeria will depend on implementation of these interventions by stakeholders.

Keywords: Cervical cancer; Screening uptake; Determinants; Interventions; Women 
Abbreviations: ACCP: Alliance for Cervical Cancer Prevention; AIDS: Acquired Immunodeficiency Syndrome; ASIR: Age Specific Incidence Rate; ASMR: Age Specific Mortality Rate; CIN: Cervical Intraepithelial neoplasia; DALY: Disability Adjusted Life years; GCPS: Guide to Community Preventive Services; HIV: Human Immunodeficiency Virus; HPV: Human Papilloma virus; IEC: Information, Education, communication; IARC: International Agency for Research on Cancer; MPM: Mobile Phone Messaging; NCC: Nigerian Communications Commission; NPC: National Population Commission; SMS: Short Message Service; UICC: Union for International Cancer Control; VIA: Virtual inspection with Acetic acid; VILI: Virtual Inspection with Lugol's Iodine; WHO: World Health Organization

\section{Introduction}

Cervical-cancer screening is an effective technique for detecting cervical-cancer before its symptoms occur, yet the uptake of such screening in developing countries like Nigeria is low [1]. This study reviews interventions that could be implemented in Nigeria in order to improve cervical-cancer screening uptake and reduce cervicalcancer mortality.

\section{Background}

In developed countries, organized cervical-cancer screening which ensures that women at risk of cervicalcancer are screened at intervals exists [2]. This is unlike developing countries, like Nigeria, where opportunistic cervical-cancer screening, taking advantage of a woman's visit to a health facility is available [3-5]. Lack of organized cervical-cancer screening programme and wrong perception of the community towards cervicalcancer screening have led to low uptake of cervical-cancer screening and high cervical-cancer death in Nigeria [6-9].

Cervical-cancer is the abnormal change of cells of the cervix $[10,11]$, about $99.7 \%$ cases is caused by Human Papilloma Virus (HPV) transmitted sexually $[12,13]$. HPV causes gradual changes in the cervical cells- cervical intraepithelial neoplasia (CIN 1-3) before progressing to cervical-cancer [14], providing an opportunity for early detection through screening [15].

\section{Cervical Cancer Risk Factors}

A number of factors have been found to expose women to cervical-cancer. These factors include; exposure to HPV, early age at sexual contact, early marriage, multiple sex partners, multiparty, co-infection with Human immunodeficiency Virus (HIV) and Chlamydia, dietary deficiencies, smoking, alcoholism, use of oral contraceptive and immunosuppressant, and low cervicalcancer screening uptake [16].

\section{Burden of Cervical-Cancer}

Globally, an estimated 528,000 new cases of cervicalcancer and 266,000 deaths occur annually, $85 \%$ of which is in developing countries [17]. In sub-Saharan Africa, cervical-cancer is responsible for $20-25 \%$ of all women cancers [17]. Western Africa has fifth highest burden of cervical-cancer with age specific incidence rate (ASIR) of 29 per 100,000 women and age specific mortality rate (ASMR) of 19.6 per 100,000 women in regional ranking [17]. Cervical-cancer ranks second after breast-cancer among women cancers in Nigeria, accounting for $21.8 \%$ new cases and $20.3 \%$ deaths in 2012 [7-17].

The impact of cervical-cancer is enormous. It causes death of women and weakens the family/community fabric [18]. In Nigeria, cervical-cancer results in about \$3.3 million/ Disability Adjusted Life years (DALYS) lost annually in terms of man-hour loss and medical costs [47].

\section{Cervical-Cancer Screening Uptake in Nigeria}

Cervical-cancer screening uptake measures the number of eligible women to be screened within a population that actually got screened [2]. Though a single visit cervicalcancer screening could save more than 6,000 Nigerian women annually, uptake is low [8]. Out of thirteen different studies on cervical-cancer screening uptake in Nigeria reviewed, nine $(69.2 \%)$ showed cervical-cancer screening uptake $<5.3 \%$, while four $(30.8 \%)$ recorded uptake $>5.3 \%[4-6,8,9,19-26]$ against $75 \%$ with screening rate $>5.0 \%$ in developed countries [18].

\section{Determinants of Low Cervical-Cancer Screening Uptake in Nigeria}

Determinants of low cervical-cancer screening uptake in Nigeria include; wrong perceptions about cervicalcancer and cervical-cancer screening due to low level of knowledge about the disease and screening as a preventive measure $[4,8,9,19,24,25]$. Other determinants include; inadequate cues to cervical-cancer screening uptake, low self-efficacy and unavailability, inaccessibility, unaffordability and unacceptability of cervical-cancer screening $[6,20,23,26]$. 


\section{Methodology}

\section{Data Sources/Search Engine}

Global health, Pop line and PubMed databases were used to access a wide coverage of literature. Generic publications were accessed through manual search of WHO, IARC and ACCP websites. Additional literature were obtained from Eldis search engine through snowballing of the reference section of some articles selected from databases and websites for other relevant publications. Relevant text-books and publications from libraries in the University of Leeds and WHO in Geneva were used.

\section{Keywords/Search Strategy}

Keywords for the study were combined and articles searched shown in Table 1 and Figure 1. Selected articles from Global Health were saved in an auto-alert format for access to new publications. There were minor modifications of the keywords for retrieval of information from websites, because certain words like feasibility, accessibility, acceptability, quality and effectiveness were required to generate further information.

\begin{tabular}{|c|c|c|c|c|}
\hline \multirow[b]{2}{*}{$\mathbf{S} / \mathbf{N}$} & \multirow[b]{2}{*}{ Keywords } & \multicolumn{3}{|c|}{ Databases } \\
\hline & & $\begin{array}{l}\text { Global } \\
\text { health }\end{array}$ & Popline & PubMed \\
\hline i. & $\begin{array}{l}\text { Determin* OR } \\
\text { predictors* }\end{array}$ & 411014 & 53686 & 2682952 \\
\hline ii. & $\begin{array}{l}\text { Cervica Cervical } \\
\text { cancer* OR Human } \\
\text { papilloma virus*l } \\
\text { cancer* OR Human } \\
\text { papilloma virus* }\end{array}$ & 10509 & 156 & 32645 \\
\hline iii. & $\begin{array}{l}\text { Screen* OR early } \\
\text { detection* OR pap } \\
\text { smear* OR visual } \\
\text { inspection* OR } \\
\text { prevention* }\end{array}$ & 230422 & 98522 & 1752370 \\
\hline iv. & Wom* OR female* & 307335 & 161674 & 6772079 \\
\hline v. & $\begin{array}{c}\text { Developing countr* } \\
\text { OR Nigeria* OR } \\
\text { Africa* } \\
\end{array}$ & 566080 & 309840 & 344319 \\
\hline vi. & I, ii, iii, iv, v [AND] & 419 & 34 & 254 \\
\hline vii. & Referenced & 12 & 5 & 30 \\
\hline
\end{tabular}

Table 1: Literature search strategy.

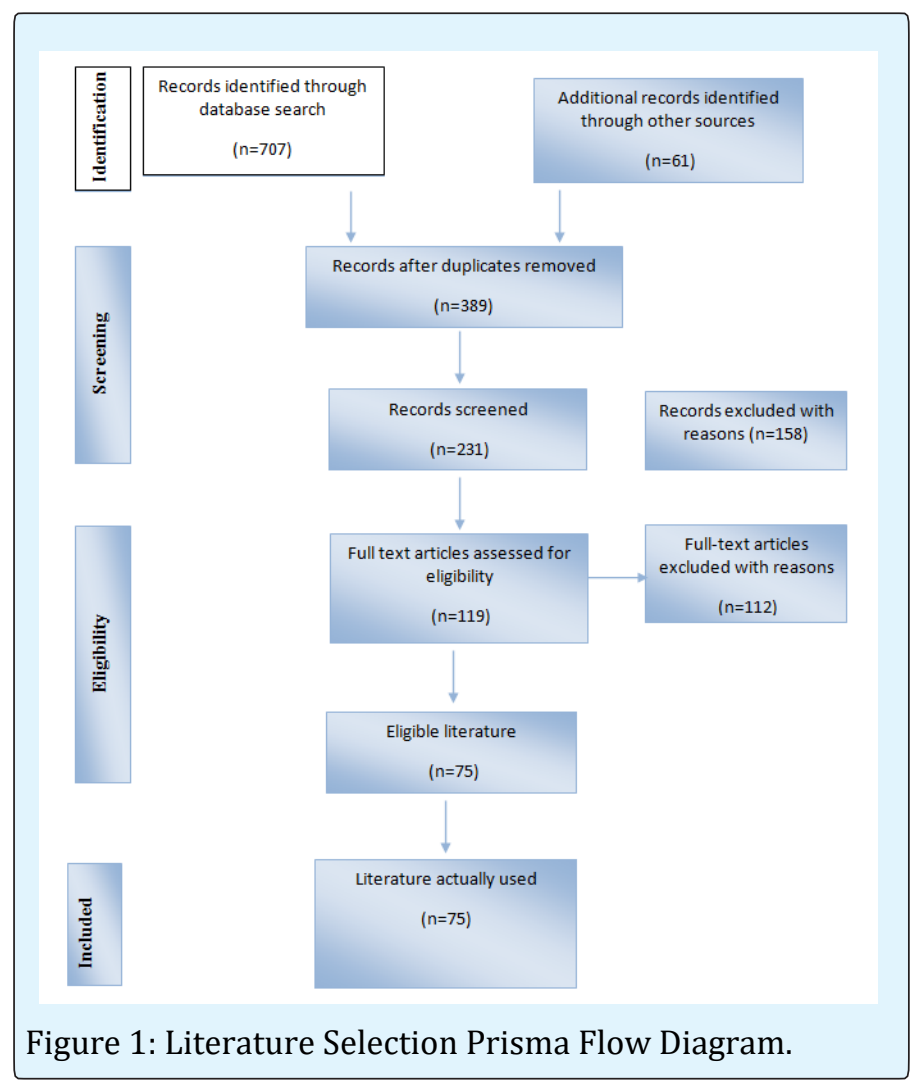

\section{Inclusion and Exclusion Criteria}

Content: The titles and abstracts were used to select full text publications addressing the determinants of low cervical-cancer screening uptake and/or interventions for improving uptake. Interesting articles without full text where obtained from relevant journal websites using Eldis search engine. Peer-reviewed publications were given priority.

Language: Only literature published in English were reviewed.

Time: Literature published after 1990 were reviewed because of increased research in cervical-cancer starting from the 90's.

Publications not meeting the above criteria; that gave technical/medical details of cervical-cancer interventions, were based on experimental laboratory or animal studies or context not similar to Nigeria were excluded.

\section{Selected Literature}

Seventy-five references were reviewed. Endnote was used to sort database literature (Table 1) and fourtyseven referenced. Twenty-eight articles were referenced from websites, snowballing of references and textbooks. Two publications obtained from auto alert were not used 
because information they contained were not different from the seventy-five referenced.

\section{Study Limitations}

The policy on national cervical-cancer prevention in Nigeria was either non-existent or not accessible for retrieval of information on government plan about the disease. However, robust evidence showed that there is need to improve cervical-cancer prevention services. Again, the full texts of certain publications were inaccessible and could not be used. The review focused on interventions for improving cervical-cancer screening uptake, rather than the determinants and interventions because a comprehensive review of the determinants of low cervical-cancer screening uptake had been undertaken and findings summarized here. Again, the study did not cover all the health system interventions like governance, finance and Health information management which are important in improving cervicalcancer screening uptake.

\section{Analytical Tool}

Interventions for improving cervical-cancer screening uptake was analyzed using Walley and Wright appraisal criteria in order to determine their effectiveness and feasibility in Nigeria [27].

The criteria include:

- Technical effectiveness: The extent to which the intervention could improve cervical-cancer screening uptake among women.

- Organizational feasibility: The ease with which the strategy could be implemented.

- Gender, cultural and political feasibility: The acceptability of the strategy in the socio-political context.

- Cost effectiveness: The cost of implementing the strategy/benefit accruing from it.

\section{Analysis of Interventions for Improving Cervical Screening Uptake in Nigeria}

Wrong perception and low knowledge about cervicalcancer and cervical-cancer screening, and inaccessibility to cervical-cancer screening were the major problems associated with low screening uptake among Nigerian women [4-6,8,9,19-26]. Broad interventions identified for addressing these determinants are; intervention aimed at correcting perception and improving knowledge and intervention aimed at increasing access to cervical-cancer screening services.

\section{Interventions Aimed at Correcting Perception and Improving Knowledge about Cervical-Cancer and Cervical-Cancer Screening}

Educating women and the community about cervicalcancer, cervical-cancer screening and treatment as well as educational training for health workers on screening and communication skills could have a major impact in correcting perceptions and increasing knowledge and skills among women, community and health-workers respectively [28]. Educational strategies that could be explored include; group education, one-on-one education, mobile phone messaging and mass media $[28,29]$.

\section{Group Education}

Information about a disease and its preventive measures could be conveyed to a population group in order to empower them to take necessary actions to improve their situation [30]. Integrating cervical-cancer education into secondary and medical schools contributed to the reduction in the incidence of cervicalcancer in Rwanda [31].

Technical effectiveness: In a study involving 350 women (divided into two arms) carried out in Nigeria, aimed at evaluating the effect of a group educational programme on awareness of cervical screening, there was an increase in knowledge about cervical-cancer and cervical-cancer screening among the intervention group exposed to educational programme compared with the control (not exposed to educational programme), suggesting that expanding the programme may increase knowledge and cervical-cancer screening uptake in the country [4]. Similarly, among a population subgroup of Korean women with low cervical cancer knowledge and low cervicalcancer screening rate similar to Nigeria, $66 \%$ increase in uptake of screening among the intervention group, against 5\% among the control after group education was reported [32]. A meta-analysis to ascertain the effectiveness of varieties of intervention methods to promote Pap test screening among ethnic minority Asian and African American women equally showed that community-based group education was significant in improving cervical screening with large effect size of 0.167 [95\% CI=0.057, 0.278] [33]. Credence was given to group education in increasing screening uptake among women in studies carried out in Korea, Nigeria and Tanzania $[12,22,33]$. 
Contradicting the report that increasing knowledge increases screening uptake, it was noted that increasing knowledge does not in all cases translate to change in behaviour [36], and may explain why $32.6 \%$ out of $90.1 \%$ respondents with the right knowledge of severity of cervical-cancer ever screened in a study carried out in Nigeria [26]. One would expect a higher screening rate involving nearly all the respondents with the right knowledge about the disease and its screening. Having knowledge about cervical-cancer without access to cervical-cancer services does not improve screening uptake [36]. Using lessons learnt from HIV/AIDS prevention and control, a chronic disease like cervicalcancer, HIV screening uptake was low in developing countries when services were not decentralized, treatment unavailable and HIV message was 'AIDS kills' [36]. People never bothered screening since there was no HIV cure. With the decentralization of service, treatment availability and change of message to 'AIDS is not the end of life', people became willing to screen realizing that effective treatment for healthy life was accessible [36]. Therefore, service accessibility, affordability, quality and skills of health-workers are basic in determining the effectiveness of a group education in improving uptake of cervical-cancer screening. Efficiency of health-workers was observed to have increased after educational training with expectation that this will increase screening uptake by women [36].

Organizational Feasibility: Group education could be conducted by health educator or trained layperson (peer educator, positive deviant, survivor of cervical-cancer), for a variety of women groups and in different settings such as; during funerals, carnivals or festival, in community square, public meetings or markets, churches, workplace and health facilities [28]. The use of different presentation styles like questions and answers, puppet shows and street plays, songs about cervical-cancer prevention in traditional melodies, street theater and music, and various aids such as loudspeakers and information, education and communication (IEC) materials- flipcharts, flyers, brochure make for organizational flexibility and feasibility $[3,28,37]$. These notwithstanding, attrition of trained lay educators who are usually volunteers questions the sustainability of the approach [28].

Since education focuses on a group, developing and tailoring information to address the overall group does not in all cases meet individual recipient's characteristics, aspirations or beliefs and therefore may require special skills or tools, raising concerns on organizational feasibility of group education especially in rural and hardto-reach areas [30]. Hence, involving the target group in educational programme design and implementation will help tailor the programme to the essential cultural and group perspectives based on demographic, psychosocial and structural factors that influence perception [36].

Gender, cultural and political feasibility: Group education is acceptable by both genders and different cultures, and could apply across a range of settings and populations, provided it is adapted to the need of the target populations [30]. The group education intervention for improving cervical-cancer screening uptake organized with community involvement in selected countries (El Salvador, Thailand, Peru, India, Korea, Ghana, Tanzania and Kenya) with diverse sociocultural context, increased uptake of cervical-cancer screening [28,34,38], a sign that it could have gender -cultural acceptability and political feasibility in Nigeria. From personal experience, the existing social structures (women, men, religious and cultural associations) in Nigeria could support group education and make for gender, cultural and political feasibility.

Cost effectiveness: In a randomized controlled trial to calculate the costs and cost-effectiveness of implementing group education to motivate women to obtain a Pap smear among the Chinese North American women with high cervical-cancer prevalence and low screening rate, the intent-to-treat cost for each additional woman to be screened for a Pap test was $\$ 415$ in the group education arm and $\$ 676$ for the Direct Mailing arm, noting that group education intervention, though more expensive overall, was more cost-effective than the mailing intervention, calculating cost-effectiveness as the incremental cost of screening each additional woman between an intervention arm and the control arm [39]. The use of volunteers who are paid stipend could further reduce the cost of group education [40,41]. However, attrition of volunteers at the long run with constant recruitment, orientation, training and supervision may reduce the cost effectiveness of the intervention [42]. In addition to attrition, group education may be expensive and time-consuming as IEC materials may be costly to produce, fall short of the desired effect following the dynamics of the society, thereby requiring reprinting, while educational programme impact evaluation requires a long time frame and substantial resources to measure [28]. 


\section{One-On-One Education}

One-on-one education is the communication of information to individual clients by a healthcare professional, health educator, a lay health advisor or volunteer either through phone and face-to-face contact at the health facility or during home visit [43].

Technical effectiveness: Strong evidence exists to show that one-one-one communication is effective in improving cervical screening, possibly because it is participatory and empowering since communication is shared and understanding established [30]. In Kenya and Brazil with similar low cervical-cancer screening uptake like Nigeria, cervical-cancer screening among women increased by $42 \%$ and $75.4 \%$ respectively after one-on-one education during a home visit $[12,44]$. In addition to increasing cervical screening uptake, one-on-one education presents opportunity for a holistic focus on women's physical, mental, and emotional health as it provides a more private setting where women could discuss any concerns or confusion they have with trained community health workers for assistance [28].

Organizational feasibility: One-on-one education could be delivered by a health professional, health educator or by a trained layperson such as community Health Worker/ Community Health Volunteer (CHW/CHV) or peers in varieties of settings- health facilities, community, church, worksite, or household [45]. Information to be communicated may be untailored to address the overall target population or tailored according to individual recipient's characteristics, beliefs, or perceived barriers to screening, therefore may require special skills or tools to develop [30]. This raises concerns on organizational feasibility of this approach especially in rural and hard-toreach areas.

Gender, cultural and political feasibility: One-on-one education is gender-culturally acceptable and politically feasible in a wide range of settings if tailored to the context where it will be implemented [29].

Cost effectiveness: The cost effectiveness of implementing one-on-one education is a source of concern considering the huge resources (money, manpower and materials) that would be required to reach about 36.6 million women aged $20-65$ years who are at a great risk of cervical cancer in Nigeria $[46,47]$. In a large randomised trial of one-on-one educational and decision support for patients with menorrhagia (associated with the reproductive system of women like cervical cancer) which included a video of the treatment options and outcomes, an accompanying booklet, and a structured interview with a nurse to help patients express their preferences, a reduced hysterectomy rates and lower mean overall service costs- $\$ 1566$ ( $£ 794$; $€ 1178$ ) was recorded in the intervention group compared with $\$ 2751$ in the control group (mean difference \$1184; 95\% confidence interval $\$ 684$ to $\$ 2110$ ) [48].

Low retention rate of volunteers which leads to frequent recruitment and training of educators; in addition to quality-control measures, duration of educational sessions, travel for in person education, and professional backgrounds of educators may further increase the costs and impact feasibility and sustainability of implementing one-on-education [30].

\section{Mobile Phone Messaging (MPM)}

MPM is the use of phone message popularly called short message service (SMS) or text messaging to transmit information from one mobile phone (the sender) to another (the receiver) [49].

Technical effectiveness: Mobile phone text messaging was found to be effective in increasing uptake of cervical screening across a wide range of population with mobile phone network through awareness creation about cervical cancer and its preventive measures [49]. Its effectiveness was reported in controlling a number of public health challenges. For instance; "Learning about Living" is sms-based intervention by MTN that provides information about relationships and HIV/AIDS among young Nigerians [50]; Uganda's 'Text to changes' and South Africa's 'Masiluekis' send SMS message to create HIV/AIDS awareness, Philippines's 'Phoned Pill Reminder projects' sends SMS for tuberculosis treatment, Tanzanian Text to Change (TTC) and Maternal and Child Health Integrated Program (MCHIP) to increase uptake of medical male circumcision (MMC) are interventions using MPM with huge success $[49,51,52]$. Since MPM is effective in many developing countries and for several public health challenges, it is likely to improve cervical-cancer screening in Nigeria.

Organizational feasibility: With about nine mobile network operators in Nigeria, $91.15 \%$ teledensity and penetration rate of $70 \%$ over a population of 168.8 million in 2013, applicability of mobile phone messaging in cervical-cancer education and cervical screening promotion could be feasible $[53,54]$. The expansion and widespread of social connectivity of mobile phone to all 
type of people in the world expand the opportunity for the use of MPM in awareness creation [55]. However, the level of women literacy (54\%) and family ownership of mobile phone $(50 \%)$ in Nigeria are potential barriers to national coverage of all the women using MPM since inputting, displaying, transferring and processing of data is challenging for people with low levels of literacy, while those not owning mobile phone may be excluded questioning equity in service delivery $[47,55]$. The decreasing cost of phone is increasing ownership [55]. From personal experience, women with low literacy level usually ask their confidants to read and interpret to them SMS that enters their mobile phone(s). Another potential threat to organizational feasibility of MPM is that despite increasing network coverage, the mobile network connectivity in most rural areas of developing countries, including Nigeria is unreliable; signal often weak, making it hard to use mobile phone and placing women in rural area at disadvantage- inequity [55]. Personal experience showed that Nigeria Communication Commission and network operators are working hard to ensure quality mobile network to subscribers, with huge penalty on defaulting providers.

Gender, cultural and political feasibility: The graphics quality, reliability and speed of short message service (SMS) data transfer, confidentiality and the use of varieties of language tailored to the target audience, based on unique characteristics and the outcome of interest or untailored to address the overall target population are acceptable by women across all culture, ethnicity, religion and social divide [2,49,55-58].

Financial feasibility and cost effectiveness: The cost of most handsets and service is low and continues to decrease, making it possible for the disadvantaged people in rural and poor resource settings to own a mobile phone $[49,55]$

\section{Mass Media}

Television, radio, newspapers, magazines, and billboards could be used to communicate information about cervical cancer and cervical screening in largerscale intervention campaigns targeting large group of people [2].

Technical effectiveness: Though usually used as a component of an intervention, mass media is effective in improving cervical screening uptake when used alone [30]. In a small study conducted in Nigeria, media followed by hospitals were the major source of cervical cancer or Pap smear test information and increased uptake of cervical cancer screening when a survivor movie star was brought in to tell her story about the disease [8]. In South Africa, a photo-comic and a radiodrama increased cervical screening uptake by $7 \%$ and $6 \%$ respectively [59]. Evidence from the rural centre of $\mathrm{New}$ South Wales with low knowledge of cervical cancer and low screening uptake similar to Nigeria showed that mass media improve cervical screening uptake by $13.3 \%$ [60]. Also media-led education intervention increased recognition of and the likelihood of cervical-cancer screening uptake among Vietnamese-American women in Alameda and Santa Clara Counties in northern California where perception about cervical cancer was incorrect and screening uptake low [61]. A rapid acceleration in demand for Pap smears in an underserved Latino community of East Los Angeles like Nigeria following the showing of videos in waiting rooms of public health clinic facilities on the need for cervical screening was reported [63]. The effectiveness of mass media varies among various ethnic populations and methods of delivery [40]. The non-participatory nature of mass media is a concern about its potential to change behaviour.

Organizational feasibility: Limited resources and infrastructure hampers organizational feasibility of mass media intervention [43]. With 46\% women illiteracy level, poor use of mass media with about one in ten women reading a newspaper weekly, two-fifths watching television and $56 \%$ listening to radio at least once a week in Nigeria [47], there doubt on the organizational feasibility of this approach. Personal experience showed that not every woman in the rural areas has access to mass media (Television and radio). Where mass media exist, transmission signal and electrical power supply could be fluctuating, while alternative energy sources such as batteries and generators may be expensive to afford or sustain.

Gender, cultural and political feasibility: Mass media is acceptable to males and females of different cultural background depending on the type and development of documentary material [62]. However, males are more in possession of mass media than females in most Nigerian culture, questioning its gender and cultural feasibility, especially with the disease affecting women and not men (personal experience).

Cost effectiveness: The cost-effectiveness of mass media depends on the type and development of documentary material [62]. 


\section{Interventions Aimed at Increasing Access to Cervical-Cancer Preventive Services}

Interventions addressing the entire health systemgovernance, workforce, service delivery, finance, information, medicines, vaccines and technology are important in improving screening uptake, but beyond the scope of this study. Mobile cervical-cancer prevention clinic (education, counseling, screening, treatment, referral and follow-up services) and health care intervention i.e. integration of cervical-cancer services (screening, treatment, counseling, referral and follow-up) into existing programme (e.g. maternal and child health or HIV/AIDS) in primary health care which increase access to services are discussed $[63,64]$.

\section{Mobile Clinic}

Mobile cervical cancer prevention clinic offers clinical services in alternative, nonclinical settings such as worksites and the hard-to-reach rural regions in order to reduce structural barriers like; time spent or distance between service delivery settings and target populations, modify hours of service to meet client needs and eliminate or simplify administrative procedures that impede access to services [65]. Sufficient evidence shows that mobile clinic reduces structural barriers, increases uptake of cervical-cancer screening and applies across a range of settings for women with limited access to services provided it is adapted to target populations and delivery contexts [30-66].

\section{Technical Effectiveness}

Among rural Thai women, mobile unit increased Pap smear uptake from $19.9 \%$ in 1991 to $70.1 \%$ by 1997 , identifying $85.2 \%$ CIN III and all invasive cancers [67]. In Brazil, a $40 \%$ increase in positive Pap smears with cancer detection rate nine times higher than observed in routine screening using mobile unit was recorded [68]. An increased screening uptake of $75.4 \%$ similar to that reported in India was recorded in Brazil using mobile clinic $[20,44]$, while in South Africa, a total of $97 \%$ of patients referred for colposcopy complied because it could be obtained at the same visit and venue where mobile cervical-cancer prevention service was rendered, unlike $34 \%$ compliance when referred to the nearest colposcopy clinic, $20 \mathrm{~km}$ from the screening site [69]. Therefore, mobile clinic is likely to be effective in increasing cervical-cancer screening uptake in Nigeria, especially with $60-70 \%$ of Nigerian women residing in rural areas where access to services is limited [47].

\section{Organizational Feasibility}

Mobile clinic intervention requires a mix of professionals and lay health-workers, one or more secondary supporting measures such as printed Information Education communication (IEC) and outreaches in order to sensitize and mobilize women and the community [70]. Mobile clinic is flexible and could target market days, distant villages, work sites, with trained nurses or community health-workers/volunteers delivering services under supportive supervision of a professional with participation of the women, community and community leaders [30]. Community involvement increases ownership and encourages women unlikely to utilize services to do so seeing that respected and trusted community stakeholders are involved [65]. Using virtual inspection with acetic acid (VIA) or with Lugol's iodine (VILI) with cryotherapy which is simple, and requires a single visit to minimize loss to follow-up and no electricity makes organization of mobile clinic feasible [28].

Lack of commitment from leaders and sustainability of the intervention are mobile clinic issues of great concern [71]. Long waiting time during mobile clinic could be discouraging and may affect screening uptake [72]. Considering the population of a target area and scheduling appropriately based on the capacity of the clinic in terms of resources was suggested to reduce waiting time by women [28].

\section{Gender, Cultural and Political Feasibility}

Making services accessible and reducing the number of visits makes mobile clinic acceptable by women [69]. However, gender and cultural acceptability is questioned when screening is carried out by a male [45], though some women wouldn't mind provided the male healthworker is not a familiar person [73]. A personal discussion with a Somalian showed that some women may not feel comfortable being examined and treated in a van as this approach is not customary, calling for education for acceptance of the intervention. In Ghana low political commitment for cervical-cancer prevention was reported, though more cost effective, breast cancer was prioritized [36]. With competing health and security needs, commitment is required from the government, international and local organizations for mobile cervicalcancer prevention clinic in Nigeria.

\section{Cost Effectiveness}

Since mobile clinic is cost-effective, offering a singlevisit service, reducing cost of transportation and 
screening, while minimizing loss to follow up especially for developing countries like Nigeria with shortage of health-workers and unavailability of cervical-cancer services in rural areas [28.36,74]. Simple and little equipment required for mobile clinic makes the intervention cost-effective [36].

\section{Integration of Cervical Cancer Services into Existing Programme in Primary Health Care (Healthcare Intervention)}

Integrating cervical cancer prevention (education, counseling, screening, treatment and referral) into existing reproductive health or HIV/AIDS services in primary health care system makes services more accessible especially to women in rural areas and ensures community ownership [63]. HIV screening in developing countries increased with decentralization of services from tertiary and secondary to primary health facilities [36].

Technical effectiveness: The effectiveness of integrating cervical-cancer prevention into primary health care depends on the involvement and commitment of the community in ensuring that cervical cancer is demystified, women reached and supported use services especially by their husbands [36]. Integration of cervicalcancer screening into antiretroviral therapy programmes in Zambia allowed early detection of cervical-cancer in HIV-infected women, expanding availability of care for women at risk of one or both conditions, thereby ensuring wider programme impact [65]. The usefulness of cryotherapy in primary health care further makes healthcare intervention $80-90 \%$ effective in cervicalcancer prevention [63].

Organizational feasibility: Integrating cervical-cancer prevention into an existing HIV/AIDS programme uses the existing resources with additional support that is peculiar to cervical-cancer services, instead of unnecessary duplication and inefficient use of resources associated with running vertical programmes [65]. In Rwanda, health centre nurses and community health workers carryout VIA and cryotherapy after being trained and suportively supervised [32]. In India, cervical-cancer was integrated into local child welfare clinics, with men being part of a team that counsel eligible women and their husband at health facilities and because the facility was accessible it was not difficult for men to join although activities did not specifically target them [28].
Cervical-cancer screening amidst other health priorities (HIV/AIDS, tuberculosis, malaria) that make cervical-cancer prevention look unimportant; management of health facilities by managers without public health training, skills or community perspective; and lack of dedication from staff or volunteers and attrition due to limited funding/incentive may affect the organizational feasibility of health care intervention in Nigeria [28].

Integrating cervical-cancer services into primary health care in Nigeria will require much effort since the current primary health care is skewed towards maternal-child care and infectious diseases control especially HIV/AIDS, tuberculosis and malaria. Reorientation and strengthening involving policy; access to medicine (morphine for palliative care) and appropriate technology for screening, diagnosis and treatment; information systems; recruitment and training of health workforce putting in perspective acute health workforce shortage in Nigeria, finance, service delivery including patient counseling, education, and referral system for those who develop cancer is necessary [36].

Gender, cultural and political feasibility: With the involvement of the community in the design and implementation of health care intervention, there may be gender and cultural acceptability of healthcare intervention [63]. Cervical-cancer screening when there is no apparent need may be gender and culturally unacceptable, requiring education to change [28]. The cost-effectiveness of cervical-cancer preventive services notwithstanding, political will and funding may be lacking as was evident in cervical-cancer prevention in Ghana [36]. Political feasibility of health care intervention is influenced by the power of the actors, organizations and individuals involved; the extent to which the policy community agrees on causes and solutions of the issue; the political context including global governance/favorable political opportunities; and the extent to which there are clear measures of the severity of the problem and effective interventions [36].

Cost effectiveness: Quality cervical-cancer screening with high coverage of women in the higher risk age group (30-45 years) is the basis of cost effective cervical-cancer screening [75]. Cervical-cancer life time risk reduction of about $25-36 \%$ at $<\$ 500$ per year of life saved was reported if a large number of never-screened women at the age of 35 years are screened, increasing further by $40 \%$ if two screenings uptake occurs at 35 and 40 years, noting that high coverage that underpins cost 
effectiveness could be achieved when cervical-cancer prevention services are accessible in health centres [36]. The cost effectiveness of integrating cervical-cancer prevention service into primary health care increases further when the service is integrated with other existing programmes than stand-alone programme explained earlier [64].

A World Bank analysis suggests that cervical-cancer screening using Pap smear test costs about $\$ 100$ per disability-adjusted life-year (DALY) compared with $\$ 2,600$ per DALY for cervical-cancer treatment and palliative care, reducing the incidence of cervical-cancer by $90 \%$ where screening quality and coverage are high [63]. With VIA or VILI reported to be cheaper than Pap smear test [76], the cost per DALY is expected to be < \$100/DALY for similar outcome. The low cost of cryotherapy with great benefit in health centres increases the cost effectiveness of health care intervention [63]. As stated earlier, cost-effectiveness does not in isolation determine the political health agenda and may require lobbying and sensitization of decision-makers.

The summary of the analysis of interventions for improving cervical-cancer screening uptake using a subjective grading system is presented in (Table 2). Group education, mobile clinic and healthcare interventions are more effective and feasible, however could be supported by one-on-one, mobile phone massaging and mass media.

\begin{tabular}{|c|c|c|c|c|c|c|c|}
\hline \multirow{2}{*}{ Intervention strategies } & \multicolumn{2}{|c|}{ Technical effectiveness } & \multicolumn{2}{c|}{$\begin{array}{c}\text { Organizational } \\
\text { feasibility }\end{array}$} & $\begin{array}{c}\text { Gender, cultural } \\
\text { and political } \\
\text { feasibility }\end{array}$ & $\begin{array}{c}\text { Cost- } \\
\text { effective } \\
\text { ness }\end{array}$ & $\begin{array}{c}\text { Overall } \\
\text { (15) }\end{array}$ \\
\cline { 2 - 7 } Interventions aimed at correcting perception, improving self-efficacy and knowledge about cervical- \\
cancer/screening
\end{tabular}

Keys: 0 - Not effective/feasible; 1 - Least effective/feasible; 2 - Moderately effective/feasible; 3 - Very effective/feasible Table 2: Appraisal of intervention strategies for improving cervical-cancer screening uptake among Nigerian women.

\section{Conclusion}

Education of women, health-workers and the community about cervical-cancer and cervical-cancer screening using group approach, supported by one-onone education, mass media and mobile phone messaging are important in correcting perception and improving knowledge of women and skills among heath-workers. Mobile cervical-cancer prevention clinic and integration of cervical-cancer prevention services into an existing maternal and child health or HIV/AIDS programmes in primary health care could increase access to cervicalcancer screening. It is therefore recommended that stakeholders should be committed to implementing these interventions with the involvement of the Nigerian communities in order to improve cervical-cancer screening uptake and reduce the burden and impact of the disease among Nigerian women.

\section{Acknowledgement}

The authors acknowledge with thanks the staff and management of Nuffield Centre for International Health and Development, Leeds Institute of Health Sciences, University of Leeds, United Kingdom and indeed everyone who contributed to the success of this study. 


\section{Conflict Interest}

The authors declare that there is no competing interest and is responsible for the content and writing of the paper.

\section{References}

1. World Health Organization (2013) Human Papilloma Virus and cervical cancer.

2. Jepson R, Clegg A, Forbes C, Lewis R, Sowden A, et al. (2000) The determinants of screening uptake and interventions for increasing uptake: a systematic review. Health Technol Assess 14(4): 1-133.

3. Wright KO, Faseru B, Kuyinu YA, Faduyile FA (2011) Awareness and uptake of the Pap smear among market women in Lagos, Nigeria. J Public Health Afr 2(1): e14.

4. Nwankwo KC, Aniebue UU, Aguwa EN, Anarado AN, Agunwah E (2011) Knowledge attitudes and practices of cervical cancer screening among urban and rural Nigerian women: a call for education and mass screening. Eur J Cancer Care 20(3): 362-367.

5. Ndikom C, Ofi B (2012) Awareness, perception and factors affecting utilization of cervical cancer screening services among women in Ibadan, Nigeria: a qualitative study. Reprod Health 9: 11.

6. Daniel CN, Emmanuel IN, Lydia RA, Magaji A, Siddique MS (2009) Screening for cervical cancer: Experience from a university hospital in north western Nigeria (2007-2009). Journal of Basic and Clinical Reproductive Sciences 2(1): 18-21.

7. Kolawole AO (2011) Feasible cancer control strategies for Nigeria: Mini review. American Journal of Tropical Medicine \& Public Health 1(1): 1-10.

8. Hyacinth HI, Adekeye OA, Ibeh JN, Osoba T (2012) Cervical Cancer and Pap Smear Awareness and Utilization of Pap Smear Test among Federal Civil Servants in North Central Nigeria. PLoS One 7(10): e46583.

9. Ezem BU (2007) Awareness and uptake of cervical cancer screening in Owerri, South-Eastern Nigeria. Ann Afr Med 6(3): 94-98.

10. World Health organization (2014) Cancer.
11. Cancer Research UK (2014) Treatment if you have abnormal cervical cells.

12. Kahesa C, Kjaer S, Mwaiselage J, Ngoma T, Tersbol B, et al. (2012) Determinants of acceptance of cervical cancer screening in Dar es Salaam, Tanzania. BMC Public Health 12: 1093.

13. World Health Organization (2010) World: HPV and related cancers.

14. Cancer Research UK (2014) Cervical cancer stages.

15. Wright TC, Schiffman M (2003) Adding a test for human papillomavirus DNA to cervical cancer screening. N Engl J Med 348(6): 489-490.

16. Lyimo FS, Beran TN (2012) Demographic, knowledge, attitudinal, and accessibility factors associated with uptake of cervical cancer screening among women in a rural district of Tanzania: three public policy implications. BMC Public Health 12: 22.

17. Globocan (2012) Cervical cancer: Estimated cancer incidence, mortality, prevalence, worldwide.

18. Union for International Cancer Control (2011) Myth: Cervical cancer is just a health issue.

19. Eze JN, Umeora OU, Obuna JA, Egwuatu VE, Ejikeme BN (2012) Cervical cancer awareness and cervical screening uptake at the Mater Misericordiae Hospital, Afikpo, Southeast Nigeria. Annals of African Medicine 11(4): 238-243.

20. Dim CC, Ekwe E, Madubuko T, Dim NR, Ezegwui HU (2009) Improved awareness of Pap smear may not affect its use in Nigeria: a case study of female medical practitioners in Enugu, southeastern Nigeria. Trans R Soc Trop Med Hyg 103(8): 852-854.

21. Amosu AM, Degun AM, Babalola, Thomas MA (2011) Level of specific knowledge, awareness, perception, and screening behaviour regarding carcinoma of the cervix among rural women in Iwo local government area, Osun State, Nigeria. Ann Bio Res 2(2): 206-221.

22. Abiodun OA, Fatungase OK, Olu-Abiodun 00 (2014) Knowledge, perception and predictors of uptake of cervical screening among rural Nigerian women. J Public Health Epidemiol 6(3): 119-124.

23. Wright KO, Aiyedehin O, Akinyinka MR, Ilozumba 0 (2014) Cervical Cancer: Community Perception and 
Preventive Practices in an Urban Neighborhood of Lagos (Nigeria). ISRN Preventive Medicine.

24. Aniebue PN, Aniebue UU (2010) Awareness and practice of cervical cancer screening among female undergraduate students in a Nigerian university. J Cancer Educ 25(1): 106-108.

25. Chinaka CC, Nwazue UC (2013) Awareness of cervical cancer and its screening in Abakaliki, Nigeria. African Journal of Cellular Pathology 1(1): 47-51.

26. Arulogun 0, Maxwell O (2012) Perception and utilization of cervical cancer screening services among female nurses in University College Hospital, Ibadan, Nigeria. Pan Afri Med J 11: 69.

27. Walley J, Wright J (2010) Public Health: An action guide to improving health $2^{\text {nd }}$ (Edn.) Oxford University Press, New York.

28. Alliance for Cervical Cancer Prevention (2004) Improving Screening Coverage Rates of Cervical Cancer Prevention Programs: A Focus on Communities.

29. Guide to Community Preventive Services, GCPS (2009) Cancer prevention and control: clientoriented interventions to increase breast, cervical and colorectal cancer screening.

30. Sabatino SA, Lawerence B, Elder R, Mercer SL, Wilson KM. et al. (2012) Effectiveness of Interventions to Increase Screening for Breast, Cervical, and Colorectal Cancers Nine Updated Systematic Reviews for the Guide to Community Preventive Services. Am J Prev Med 43(1): 97-118.

31. Binagwaho A, Ngabo F, Wagner CM, Mugeni C, Gatera $M$, et al. (2013) Integration of comprehensive women's health programmes into health systems: cervical cancer prevention, care and control in Rwanda. Bulletin of the World Health Organization 91: 697-703.

32. Fang CY, Ma GX, Tan Y, Chi NA (2007) Multifaceted Intervention to Increase Cervical Cancer Screening among Underserved Korean Women. Cancer Epidemiol Biomarkers Prev 16(6): 1298-1302.

33. Han HR, Kim J, Lee JE, Hedlin HK, Song H, et al. (2011) Interventions that increase use of Pap tests among ethnic minority women: a meta-analysis. Psychooncology 20(4): 341-351.

34. Moskowitz JM (2007) "Health is strength": a community health education program to improve breast and cervical cancer screening among Korean American Women in Alameda County, California. Cancer Detect Prev 31(2): 173-183.

35. Ibekwe CM, Hoque ME, Ntuli Ngcobo B (2010) Perceived susceptibility of cervical cancer screening among women attending Mahalapye District Hospital, Botswana. South Afr J Epidemiol Infect 25(2): 16-21.

36. Reeler A, Qiao Y, Dare L, Li J, Zhang A, et al. (2009) Women's Cancers in Developing Countries: From Research to an Integrated Health Systems Approach. Asian Pac J Cancer Prev 10(3): 519-526.

37. Giarratano G, Bustamante Forest R, Carter CA (2005) multicultural and multilingual outreach program for cervical and breast cancer screening. J Obstet Gynecol Neonatal Nurs 34(3): 395-402.

38. Tanjasiri S, Kagawa Singer M, Foo MA, Choa M, Linayao PI, et al. 2007. Designing Culturally and Linguistically Appropriate Health Interventions: The "Life Is Precious" Hmong Breast Cancer Study. Health Educ Behav 34 (1): 140-153.

39. Thompson B, Thompson L, Chan NL, Hislop TG, Taylor VM (2007) Cost effectiveness of cervical cancer screening among Chinese women in North America. Asian Pac J Cancer Prev 8(2): 287-293.

40. Lu M, Moritz S, Lorenzeth D, Sykes L, Straus S, et al. (2012) A systematic review of interventions to increase breast and cervical cancer screening uptake among Asian women. BMC Public Health 12: 413.

41. Medley A, Kennedy C, O Reilly K, Sweat M (2009) Effectiveness of peer education interventions for HIV prevention in developing countries: a systematic review and meta-analysis. AIDS Educ Prev 21(3): 181-206.

42. Steinman $P$ (2010) Is peer education effective for HIV prevention in low- and middle-income countries? A Support summary of a systematic review.

43. Baron RC, Rimer BK, Breslow RA, Coates RJ, Kemer J, et al. (2008) Client-directed interventions to increase community demand for breast, cervical, and 
colorectal cancer screening: a systematic review. Am J Prev Med 35(1): 34-55.

44. Mauad EC, Gomes UA, Nogueira JL, Melani AGF, Lemos DL, et al. (2002) Prevention of cervical cancer in a poor population in Brazil. Fam Pract 19 (2): 189-192.

45. Ngugi CW, Boga H, Muigai AW, Wanzala P, Mbithi JN (2012) Factors affecting uptake of cervical cancer early detection measures among women in Thika, Kenya. Health Care Women Int 33(7): 595-613.

46. Kolawole A (2012) Cervical cancer prevention in Nigeria: issues arising. IEEE J Gynaecol Obstet 16: 1.

47. National Population Commission (2008) Nigeria Demographic and Health Survey.

48. Coulter A, Ellins J (2007) Effectiveness of strategies for informing, educating, and involving patients. BMJ 335(7609): 24-27.

49. Tegegne T, Weide TVD (2012) Is mHealth Viable to Ethiopia?- An Empirical Study: Proceedings of M4D, 28-29 February 2012, New Delhi, India 82-95.

50. Adoghe A (2009) Linking policy with technology: role of mobile communication technology in polio eradication initiative in Northern Nigeria. MIH Thesis. Royal Tropical Institute.

51. Hoefman B, Namirembe E, Mahler H, Tempo JB, Loggers JW, et al. (2012) "Using mobile phones to improve delivery and uptake of medical male circumcision: Experiences from north Tanzania". Proceedings of M4D, 41-45.

52. Littman-Quinn R, Chandra A, Ghose AC, Kovarik C (2012) "mHealth in Botswana: Driven by partnerships, customization and local empowerment - lessons learned on implementation, stakeholders, and sustainability in resource-limited settings". Proceedings of M4D, 113-114.

53. Nigerian Communications Commission, NCC (2014) Subscriber Statistics.

54. Nigerian Communications Commission, NCC (2013) Operators Quaterly Summary Q1 2013-Q4 2013. 2014b. Retrieved from: http://www.ncc.gov.ng/index.php?
55. Chigona W, Nyemba-Mudenda M, Metfula AS (2013) A review on mHealth research in developing countries. The Journal of Community Informatics 9: 2 .

56. Fjeldsoe BS, Marshall AL, Miller YD (2009) Behaviour change interventions delivered by mobile telephone short- message- service. Am J Prev Med 32(6): 165173.

57. Lim S, Xue L, Yen CC, Chang L, Chan HC, et al. (2011) "A study on Singaporean women's acceptance of using mobile phones to seek health information." Int J Med Inform 80(12) 189-202.

58. Siedner MJ, Bangsberg DR, Bwana MB, Haberer JE, Ware NC (2012) High acceptability for cell phone text messages to improve communication of laboratory results with HIV-infected patients in rural Uganda: a cross-sectional survey study. BMC Med Inform Decis Mak 12: 56.

59. Risi L, Bindman JP, Campbell OMR, Imrie J, Everett K, et al. (2004) Media interventions to increase cervical screening uptake in South Africa: an evaluation study of effectiveness. Health Educ Res 19 (4): 457-468.

60. Byles JE, Sanson Fisher RW, Redman S, Dickson JA, Halpin S (1994) Effectiveness of three community based strategies to promote screening for cervical cancer. J Med Screen 1(3): 150-158.

61. Taylor VM, Nguyen TT, Jackson JC, McPhee SJ (2008) Cervical Cancer Control Research in Vietnamese American Communities. Cancer Epidemiol Biomakers 17(11): 2924-2930.

62. Yancey AK, Walden L (1994) Stimulating cancer screening among Latinas and African-American women. A community case study J Cancer Educ 9(1): 46-52.

63. Sherris JD (2013) Cervical Cancer Prevention: A Strategic Opportunity To Improve Women's Reproductive Health.

64. Mwanahamutu MH, Sahasrabuddhe VV, Stringer JSA, Parham GP (2008) Integrating cervical cancer prevention in HIV/AIDS treatment and care programmes. Bull World Health Organ 86(8): D-E.

65. Agurto I, Arrossi S, White S, Coffey P, Dzuba I, et al. (2005) Involving the community in cervical cancer 
prevention programs. International Journal of Gynecology and Obstetrics 89: 38-45.

66. Cancer Association of Zimbabwe (2013) Ward Based Mobile Cervical Cancer Screening and Education Programme. A proposal submitted to: The Rotary Club.

67. Swaddiwudhipong W (1999) A mobile unit: an effective service for cervical cancer screening among rural Thai women. Int J Epidemiol 28(1): 35-39.

68. Zuben MVV, Derchain SF, Sarian LO, Westin MC, Thuler SLC, et al. (2007) The impact of a community intervention to improve cervical cancer screening uptake in the Amazon region of Brazil. Sao Paulo Med J 125(1): 42-45.

69. Megevand E, Van WW, Knight B, Bloch B (1996) Can cervical cancer be prevented by a see, screen and treat program? A pilot study. Am J Obstet and Gynaecol 174(3): 923-928.

70. World Health Organization, WHO (2014) Alliance member AEMRN delivers healthcare to remote villages in Lusaka and Kenya, through its summer mobile clinics.
71. Suba EJ, Raab SS (2011) Lessons Learned from Successful Papanicolaou Cytology Cervical Cancer Prevention in the Socialist Republic of Vietnam. Diagn Cytopathol 40(4): 355-366.

72. Agurto I, Bishop A, Sanchez G, Betancourt Z, Robles S (2004) Perceived barriers and benefits to cervical cancer screening in Latin America. Prev Med 39(1): 91-98.

73. Thomas VN, Saleem T, Abraham R (2005) Barriers to effective uptake of cancer screening among black and minority ethnic groups. Int J Palliat Nurs 11(11): 562571.

74. Alliance for Cervical Cancer Prevention, ACCP (2004) Planning and Implementing Cervical Cancer Prevention and Control Programs: A Manual for Managers ACCP.

75. World Health Organization (2013) Comprehensive Cancer Prevention and Control: a healthier future for girls and women. 